\title{
A "terra prometida": práticas de gestão, trabalho na mineração e seus impactos nas relações familiares
}

\author{
Bruna Coutinho da Silva ${ }^{1}$ \\ Pontifícia Universidade Católica de Minas Gerais (Belo Horizonte, MG, Brasil) \\ João César de Freitas Fonseca ${ }^{2}$ \\ Pontifícia Universidade Católica de Minas Gerais (Belo Horizonte, MG, Brasil) \\ Roberta Carvalho Romagnoli ${ }^{3}$ \\ Pontifícia Universidade Católica de Minas Gerais (Belo Horizonte, MG, Brasil) \\ José Newton Garcia Araújo ${ }^{4}$ \\ Pontifícia Universidade Católica de Minas Gerais (Belo Horizonte, MG, Brasil) \\ Thiago Casemiro Mendes ${ }^{5}$ \\ Pontifícia Universidade Católica de Minas Gerais (Belo Horizonte, MG, Brasil)
}

\begin{abstract}
Este artigo visa a apresentar uma pesquisa-intervenção voltada para a compreensão da relação entre família e trabalho, em uma unidade mineradora situada no Norte do Brasil. Adotam-se aqui olhares críticos da psicologia sobre o trabalho. Embora não estivessem previstos originalmente, os dados aqui relatados emergiram do campo, derivados do projeto de pesquisa-intervenção contratado pela empresa, que buscava investigar as variáveis psicossociais que diretamente afetam o trabalho de Operadores de retroescavadeira. A necessidade de buscar maior aproximação dos sujeitos de pesquisa motivou a realização de uma intervenção junto às suas famílias. Essa intervenção foi feita a partir de técnicas grupais, como rodas de conversa e visitas domiciliares, seguida pela análise das percepções dos familiares sobre o trabalho dos Operadores e sobre a relação desses com a empresa. Os resultados destacam a importância do conceito de território para compreender os processos de subjetivação das famílias; os vínculos sociais como fator psicossocial protetivo; a imbricada articulação entre o processo de gestão do trabalho e a política de benefícios sociais. Concluímos destacando a importância dos vínculos familiares para a compreensão real da atividade dos Operadores, e reafirmando a noção de centralidade do trabalho, na conformação do território.
\end{abstract}

Palavras-chave: Mineração, Trabalho, Relações familiares.

The "promised land": management practices, mining work and its impacts on family relations

This article aims to present an intervention research focused on understanding the relationship between family and work in a mining unit located in Northern Brazil. Psychology's critical views on work are adopted here. Although not originally foreseen, the data reported here emerged from the field, derived from the intervention research project contracted by the company, which sought to investigate the psychosocial variables that directly affect the work of backhoe operators. The need to get closer to the research subjects motivated the realization of an intervention with their families. This intervention was carried out using group techniques, such as conversation circles and home visits, followed by an analysis of family members' perceptions about the operators' work and their relationship with the company. The results highlight the importance of the concept of territory to understand the subjectivation processes of families; social bonds as a protective psychosocial factor; the imbricated articulation between the work management process and the social benefits policy. We conclude by highlighting the importance of family ties for the real understanding of the operators' activity, and reaffirming the notion of the centrality of work in the shaping of the territory.

Keywords: Mining, Work, Family relationships.

\footnotetext{
https://orcid.org/0000-0002-4862-2912

https://orcid.org/0000-0002-5722-1416

https://orcid.org/0000-0003-3551-2535

https://orcid.org/0000-0001-9648-9741

https://orcid.org/0000-0001-8793-8787
} 


\section{Considerações iniciais}

A região Norte é a maior das cinco regiões do Brasil, abrigando os dois maiores estados em território no país, Amazonas e Pará. O território paraense, o segundo em extensão dessa região, é coberto pela Amazônia, maior floresta tropical do mundo. Terra de paradoxos, como revelam Lemos et al. (2016) ao destacar a riqueza da biodiversidade, da natureza e da floresta, em meio aos conflitos resultantes da apropriação do minério de ferro e de outros minerais, como ouro, prata, manganês, cobre, bauxita, zinco etc.

No que se refere às forças heterogêneas que a compõem ${ }^{6}$, as leituras maniqueístas não se sustentam, e a complexidade do que ali se passa manifesta-se cotidianamente nos modos de viver e trabalhar.

A mineradora na qual realizamos nosso estudo está localizada no sudoeste do Pará, em um município cuja história está marcada por conflitos territoriais. Com a chegada da empresa no território, no final da década de 1990, o município passou a integrar um circuito de mineração que explora diferentes tipos de minérios, como ouro, cobre e ferro, há pelo menos vinte anos. Seu crescimento inicial se deu de modo desordenado, fruto tanto da migração de pessoas em busca de melhores condições de vida quanto da especulação imobiliária, especialmente nos últimos cinco anos (Santos et al., 2019).

A mineração é um ramo de atividade de alta complexidade, que possui particularidades que variam conforme o mineral extraído (ferro, ouro, bauxita etc.), a tecnologia da extração (manual ou industrializada), a regulamentação da atividade, dentre outros critérios. A instalação de uma empresa desse segmento, em determinado município, pode criar na população expectativas que muitas vezes não são atendidas. Numa análise geográfica dessa região, Palheta et al. (2017) afirmam ser um engano pensar que as atividades mineradoras irão diminuir a pobreza local ou regional. Pelo contrário, para esses autores, "o crescimento econômico é acompanhado de uma crescente periferização da cidade, com aumento da desigualdade socioespacial e intensificação de conflitos" (p. 5).

Ao analisar a atividade de mineração na Amazônia oriental, Koury (2014) afirma que a extração do minério gera ocupações precárias, pois demanda atividades que viabilizem a infraestrutura da extração de minério, como estradas, ferrovias, rodovias, usinas de beneficiamento etc. Os trabalhadores, especialmente os migrantes, são obrigados a buscarem qualquer tipo de trabalho, que, por vezes, é informal, precarizado e sem a garantia dos direitos legais. Nesse sentido, no período de implantação de projetos de mineração, usualmente empregase muita mão de obra temporária, uma vez que as atividades realizadas têm um limite estipulado para sua concretização. Estudando a viabilidade de benefícios para a população afetada por esse segmento, Villa Verde et al. (2014) destacam a necessidade de uma gestão governamental comprometida com a diversificação da economia e com o desenvolvimento de uma infraestrutura que permita a aceleração dos índices de desenvolvimento humano.

Ferraz et al. (2017), em estudo com famílias residentes em região de mineração de urânio, verificaram realidade semelhante, no que diz respeito à abertura econômica gerada pela instalação de grandes empresas, o que resultava num vácuo político e socioeconômico: geram-se empregos temporários, muitas vezes terceirizados; busca-se mão de obra qualificada não local; expõem-se populações locais a condições de vulnerabilidade, em razão da ausência ou da precariedade de políticas públicas efetivas de emprego, saúde, cidadania, segurança e meio ambiente.

Na mesma direção, Faustino e Furtado (2013), analisando o mesmo empreendimento relatado neste texto, adotam uma postura bastante crítica, em que expõem os impactos socioambientais consequentes à implantação dessa unidade mineradora, concomitantes ao aumento populacional na região, desacompanhados de desenvolvimento infraestrutural. Para essas autoras, a atividade de mineração é fator de elevada interferência unilateral, sendo

6 A complexidade da região Norte do Brasil, especialmente da região amazônica, onde se situa a unidade produtiva investigada, é extensa e sua análise extrapola os limites deste artigo. Uma das melhores análises a respeito é feita pelo documentarista João Moreira Salles, num dossiê em três partes, publicado na revista Piauí, intitulada "Arrabalde" (Salles, 2020). 
preocupante a baixa participação das populações atingidas nos processos decisórios relativos à região. Evidencia-se assim a complexidade dos territórios afetados pela mineração e as múltiplas questões sociais que podem emergir nesse cenário, foco de tensões e contradições.

É nesse contexto que situamos a intervenção, cujo resultado parcial é aqui apresentado. Originalmente, tratava-se de uma demanda organizacional para realizar uma pesquisa sobre as variáveis psicossociais que afetam o desempenho dos Operadores de escavadeira, cuja produtividade desejável seria mais de duas vezes superior à média usual do segmento. ${ }^{7}$ A pesquisa foi desenvolvida a partir de um acordo de cooperação entre a universidade e a referida mineradora, que não será identificada neste texto. ${ }^{8}$

O interesse da organização por esse grupo específico de trabalhadores - os Operadores de alto desempenho - deu-se em razão de importantes mudanças no processo produtivo. $\mathrm{Na}$ mineração clássica, usa-se o caminhão para transportar o minério de ferro escavado. Na unidade específica pesquisada, foi implantado um novo sistema, conhecido como truckless, que significa "sem caminhão", sendo todo o processo de escavação reorganizado com a incorporação de britadeiras móveis, nas quais o minério é descarregado, britado, até chegar ao local de depósito (pilha-pulmão). Segundo a empresa, ao demandar a pesquisa, não havia nenhum problema específico relacionado aos trabalhadores, como adoecimento psíquico, fadiga ou acidentes de trabalho. A pesquisa teria, portanto, caráter preventivo, em relação ao possível aparecimento desses problemas. A ideia era de que a pesquisa pudesse ser revertida em intervenções específicas, a fim de assegurar tanto a produtividade quanto a saúde dos trabalhadores, nessa nova forma de organização do trabalho.

Logo no início da investigação, os pesquisadores defrontaram-se com uma situação de intenso conflito entre os trabalhadores e a organização, o que extrapolava, de alguma maneira, a demanda inicialmente apresentada. Tratava-se de queixas de esposas e companheiras dos Operadores, em relação a uma promessa feita pela organização e não cumprida até aquele momento: a entrega de casa para os trabalhadores vindos de outra região. $\mathrm{O}$ foco da pesquisa, que originariamente estava centrado na análise da atividade dos Operadores de escavadeira, ${ }^{9}$ parecia comprometido, uma vez que os próprios trabalhadores estabeleciam como prioridade a resolução do problema mencionado. Optou-se então, como estratégia de negociação para viabilizar a pesquisa, pela realização de uma série de ações voltadas para a temática dos vínculos familiares.

Assim, a intervenção psicossocial com as famílias ${ }^{10}$ foi concebida e iniciada como oferta de um espaço de fala, de partilha de experiências, de reconhecimento da necessidade de construção de soluções coletivas, a serem negociadas com a empresa. $O$ trabalho com as famílias, nessa etapa aqui relatada, consistiu nas seguintes estratégias: (a) realização de roda de conversa para fortalecimento de vínculos entre a equipe de pesquisa e as famílias; (b) realização de quatro visitas domiciliares, como modo de aproximação dos grupos familiares dos Operadores, permitindo a análise de seu contexto vivencial, sociocultural, das repercussões do trabalho nas relações familiares cotidianas e vice-versa. Na tentativa de ampliar a voz dessas famílias e evidenciar os conflitos ali vivenciados, acolhemos o que emergia do campo, certos de que as interferências do cotidiano também fazem parte do processo de produção de conhecimento, como bem afirmam Sato et al. (2008). O registro dessas interações foi feito em anotações e relatórios realizados pelos pesquisadores ao final de cada visita de campo. Posteriormente, o material registrado foi organizado para ajustar a continuidade das intervenções.

7 A expectativa da produção média por Operador de escavadeira nesse tipo de atividade é de 3.500 toneladas de minério/hora. Para o grupo inserido na nova modalidade de organização do trabalho, a perspectiva é de 8.500 toneladas/hora. Por isso, são chamados Operadores de alto desempenho.

8 Este estudo adotou os cuidados recomendados pela Comissão Nacional de Ética em Pesquisa (CONEP).

9 Sobre os trabalhos feitos posteriormente ao relatado neste texto, voltados para a Análise da atividade dos Operadores de escavadeira, recomendamos a leitura de Fonseca et al. (2021).

10 Entendemos que o fato de algumas atividades não envolverem diretamente os filhos e filhas dos Operadores não descaracteriza o termo "família", que consideramos pertinente para nos referirmos aos vínculos pessoais dos trabalhadores. De forma recorrente, os filhos e filhas surgem nas falas e queixas, tanto dos trabalhadores quanto de suas companheiras. Aos interessados, recomendamos a leitura de Biroli (2014). 
Julgamos que as considerações iniciais deixam claro que este texto é o registro de uma pesquisa-intervenção voltada para a compreensão da relação entre família e trabalho, em uma unidade mineradora situada no Norte do Brasil. Adotam-se aqui pressupostos teóricometodológicos oriundos de diferentes autores, cobrindo um amplo espectro epistemológico, que contempla desde autores oriundos da Psicologia Social do Trabalho (Sato et al., 2017) até pesquisadores mais próximos do campo da Psicologia Organizacional (Barham \& Vanalli, 2012). Entretanto, defende-se que este estudo mantém seu alinhamento com a perspectiva crítica, por insistir no questionamento quanto às possibilidades de redução do quadro de desigualdade e assimetria a que estão submetidos os trabalhadores e suas famílias nas suas relações com a empresa, o que ratifica também um posicionamento político por parte dos pesquisadores (Bernardo et al., 2017).

Para tanto, passaremos a apresentar a revisão da literatura sobre as relações entre trabalho e família, seguida do relato sobre as orientações metodológicas adotadas. Na sequência, apresentamos os resultados obtidos com a pesquisa-intervenção, destacando a articulação com as percepções sobre o território e os conflitos entre famílias e organização, finalizando com algumas considerações pertinentes.

\section{Relações entre trabalho e família}

O olhar das organizações sobre as necessidades dos trabalhadores, derivadas de suas relações familiares, não constitui novidade. Castel (1998), discutindo a questão salarial, os benefícios e os contratos de trabalho, recupera a argumentação de Émile Cheysson, engenheiro preocupado com as questões sociais na França, no final do século XIX, para quem "Atrás da mão de obra, esta abstração econômica, há um operário, um homem com sua vida e suas necessidades" (p. 329). Cita como exemplo o operário que tem família, que reproduz a força de trabalho e favorece a estabilidade social, diferenciando-o do operário solteiro. Na mesma direção, ocorreram as práticas fordistas adotadas no início do século XX (Veronese, 2003).

Entretanto, esse debate é intensificado no início da década de 1960, com a ampliação da inserção das mulheres no mercado de trabalho ${ }^{11}$. Ou seja, foi a partir do incremento do uso da mão de obra feminina, à qual se atribuíam, e ainda se atribuem, as funções de cuidado, no ambiente doméstico, que se começou a pautar a importância de conciliação das necessidades do trabalho e da família (Barham \& Vanalli, 2012; Mioto, 2015).

Na década de 1970, sob a influência dos movimentos feministas, o debate acerca da divisão sexual do trabalho e sua relação com a família ampliou-se, contestando o lugar naturalizado da mulher exclusivamente no âmbito doméstico, e promovendo a visibilidade dos "afazeres" domésticos como trabalho não remunerado, que é sustentáculo do modelo de produção capitalista (Hirata, 1986; Mioto, 2015).

Se, por um lado, a conquista do ambiente externo de trabalho se tornou um fator de combate às discriminações de gênero, por outro lado, observa-se que as mulheres são sobrecarregadas de responsabilidades familiares e enfrentam maiores dificuldades em sua formação profissional (Hirata, 2004; Organização Internacional do Trabalho [OIT], 2009). Isso ainda é um problema social, presente em diversos países, dada a rigidez da divisão sexual de papéis, o que prejudica o desenvolvimento da autoestima e da independência financeira das mulheres, funções que se realizam a partir do papel simbólico e material do trabalho (Barham \& Vanalli, 2012).

No que diz respeito à relação entre as esferas do trabalho e da família, destaca-se a produção da Organização Internacional do Trabalho (OIT) de um conjunto de oito notas, que tratam das diversas problemáticas sobre a relação entre trabalho e família, no intuito de apresentar medidas a serem aplicadas pelas empresas, pelos sindicatos e pela própria sociedade.

11 São ainda poucas as iniciativas que se traduzem, efetivamente, na articulação da relação entre a esfera familiar e o mundo produtivo (Arruda, 1996). Exemplos disso são a construção precária de creches, a desigualdade na distribuição de tarefas domésticas, bem como a manutenção da divisão histórica das responsabilidades familiares entre cônjuges (OIT, 2009). 
Os temas orbitam em torno das responsabilidades familiares, da promoção da igualdade de gênero, das políticas de conciliação entre trabalho e família, da proteção à maternidade, das alternativas na organização do trabalho para promoção de tal conciliação, dentre outros temas (OIT, 2011).

As denominadas responsabilidades familiares são de fundamental importância para o desenvolvimento das atividades rentáveis economicamente, pois abrangem inclusive o cuidado com crianças, idosos e pessoas com deficiência. Trata-se de uma forma de regulação da vida social, fundamental para que as sociedades funcionem. Numa perspectiva mais ampla, essa regulação suscita temáticas como responsabilidade social e políticas de benefícios.

A respeito da relação entre trabalho e família, do ponto de vista gerencial, destacamos duas abordagens: a do "transbordamento" ou "contaminação" e a da compensação (Zedeck \& Mosier, citados por Barham \& Vanalli, 2012). A primeira diz respeito à ideia de que trabalho e família são duas esferas de ação completamente distintas, que não podem se envolver, pois esse contato acarretaria prejuízo das duas partes. É dessa perspectiva que deriva a ideia de que "não se deve levar os problemas de casa para o trabalho", corrente no senso comum, inclusive entre os trabalhadores com os quais conversamos. A segunda diz respeito à ideia de que trabalho e família são esferas complementares, no que concerne à realização e ao prazer, pessoais e profissionais, sendo esperada dos trabalhadores uma participação equilibrada em ambos. Esta segunda perspectiva perpassa claramente o discurso da empresa investigada, estando também presente na fala de vários sujeitos da pesquisa, o que inclusive reforçou a intenção gerencial de que os pesquisadores pudessem auxiliar os trabalhadores na obtenção desse equilíbrio. Observese que esta foi uma demanda posterior ao acordo inicial da pesquisa, situação que se repetiu algumas vezes e exigiu dos pesquisadores algumas revisões do acordo com a organização e com os trabalhadores.

Aqui, adotamos o pressuposto de que a esfera familiar e a do trabalho coexistem em um espaço de interações entre fatores psicossociais, econômicos, políticos e culturais, que se afetam mutuamente. Nesse caso, as manifestações de descontentamento, por parte de familiares dos trabalhadores, orbitaram em torno da promessa das casas e apontaram para a complexa interação entre os elementos aqui levantados. Como destacam Barham e Vanalli (2012, p. 53): "Demandas simultâneas no âmbito familiar e no trabalho, e a sobrecarga de responsabilidades ... podem gerar conflitos, sendo que esses conflitos implicam em uma variedade de custos".

Cumpre evidenciar, portanto, que o desempenho no trabalho, em diversos estudos (Barham \& Vanalli, 2012; Frone et al., 1997; Oliveira et al., 2013; Paschoal \& Tamayo, 2005), é comprovadamente afetado pela interferência das demandas familiares, sendo comum verificar a diminuição do desempenho, nas situações de conflito familiar, concomitante ao aumento do desgaste do trabalhador.

Por outro lado, verifica-se em algumas análises que a interferência da esfera familiar no trabalho parece ocorrer com frequência menor que a interferência dos conflitos relacionados ao âmbito profissional, na vivência familiar (Goulart et al., 2013; Medeiros et al., 2017; Rocha et al., 2011). Esses conflitos relacionam-se à diminuição do tempo disponível para a convivência familiar, ao cansaço e à incompatibilidade entre comportamentos esperados para o trabalho e para a família. A conclusão dos autores, de modo geral, é de que o equilíbrio entre estas duas esferas é fundamental para a qualidade de vida do indivíduo, com consequente melhora do desempenho no trabalho, a partir de interações cíclicas entre o trabalhador, a organização e a família. Cabe notar que esses estudos tratam do trabalho como uma categoria única e monolítica. Seria, pois, mais conveniente observar a atividade situada nas suas especificidades, mas essa abordagem extrapola os limites deste texto.

Curiosamente, na unidade produtiva investigada, as discussões relacionadas à temática gênero serão introduzidas por meio das já mencionadas queixas das esposas e companheiras. Até à época de elaboração deste artigo, não havia nenhuma mulher exercendo funções operacionais (no caso, Operador de escavadeira e Técnicos de campo, na mina) ou gerenciais (Supervisores e Gerentes). 
Até o momento de elaboração deste texto, a unidade produtiva tinha pouco tempo de operação (cerca de um ano e meio) e ainda não havia informação ou registro de acidentes de trabalho, nem pela empresa, nem pelos trabalhadores ${ }^{12}$. Estudos sobre a ocorrência de acidentes de trabalho usualmente abordam seus impactos sociais, inclusive sobre as famílias, tanto no segmento da mineração (Lima et al., 2015) quanto fora dele (Oliveira, 2007).

\section{Metodologia}

Este estudo se insere na linha da pesquisa qualitativa. Segundo Rey (2002), essa metodologia enfatiza a análise de microprocessos, mediante o estudo de ações sociais, individuais e grupais. Corresponde ainda a uma opção epistemológica que deve se sustentar em procedimentos que permitam a criação teórica acerca da realidade, que é em si multideterminada, dinâmica e histórica, e a elaboração das ideias e fatos procedentes do empírico. Dessa maneira, a pesquisa qualitativa, especialmente no mundo do trabalho, busca a elucidação de processos complexos, perseguindo sentidos subjetivos e processos de significação vividos no cotidiano, a partir dos quais ocorre a produção do conhecimento crítico (Ribeiro et al., 2017). O conhecimento emerge da combinação de processos de produção teórica e empírica, articulados de maneira processual e singular, e é nessa perspectiva que apresentamos a nossa empiria.

\section{Caracterização dos sujeitos da pesquisa}

Este trabalho, derivado de uma pesquisa maior, tem como foco a análise das atuações desenvolvidas com as famílias dos Operadores de escavadeira, demanda apresentada pelos trabalhadores, ratificada pela organização e surgida no encontro com o campo de pesquisa. Antes, porém, a fim de promover uma contextualização, apresentamos uma síntese de informações sobre os sujeitos da investigação, complementando o contexto da pesquisa, em sua demanda original. Observe-se que a caracterização dos grupos, especialmente das mulheres, foi feita de forma propositalmente ampla, para evitar a identificação daquelas que participaram das atividades.

O grupo de Operadores é composto por 36 homens, majoritariamente casados e originários do próprio estado do Pará. Completaram o ensino médio, alguns com formação em Técnico de Mineração, possuindo renda média familiar de três a cinco salários-mínimos. O tempo médio de empresa é de quinze anos e, na função de Operador, de oito anos. A faixa etária vai dos 23 aos 52 anos.

Outra característica importante do grupo observado é a ausência de trabalhadores terceirizados. Apesar de a terceirização ser frequente na mineração (Faustino \& Furtado, 2013), os Operadores de escavadeira, que constituíram o grupo nuclear da investigação, são todos contratados diretamente pela empresa responsável.

As mulheres e companheiras são majoritariamente pardas ou brancas, também originárias do estado do Pará. A maior parte completou o Ensino Médio e não exerce atividade remunerada regular, dedicando-se ao trabalho doméstico. A faixa etária coincide com a dos Operadores.

Realizada a caracterização dos grupos, passemos à descrição do trabalho psicossocial desenvolvido com as famílias. Este trabalho iniciou-se no mês de março de 2018, a partir de duas formas de ação: (a) realização de roda de conversa, com o objetivo de fortalecer vínculos dos pesquisadores com as famílias e os sujeitos da pesquisa. A atividade foi inspirada na metodologia das Oficinas Psicossociais, com duração média de uma hora e meia e com quinze participantes; (b) realização de quatro visitas domiciliares, cuja duração foi de trinta a quarenta minutos. As

12 Referimo-nos evidentemente ao contexto local, onde a pesquisa-intervenção foi realizada. No contexto nacional, há registros sobre graves acidentes de trabalho neste segmento, incluindo catástrofes ambientais, envolvendo a empresa investigada (Freitas \& Silva, 2019). 
visitas nos possibilitaram conhecer o cotidiano familiar, a condição das moradias, a qualidade das relações interpessoais das famílias com outros habitantes, como amigos, vizinhos e com o território.

A roda de conversa foi proposta tendo em vista a criação de um espaço de fala e de escuta qualificada das famílias sobre temas concernentes ao trabalho dos Operadores, de modo a conhecermos suas percepções e qualificar a demanda. A percepção da família sobre o trabalho dos Operadores foi elencada, inclusive para a organização, como uma variável psicossocial capaz de afetar o desempenho e a qualidade de vida desses sujeitos.

A condução do trabalho grupal se baseou na metodologia desenvolvida por Afonso (2006). Nessa técnica, inspirada na Psicossociologia ${ }^{13}$, o grupo se apresenta como espaço privilegiado para a aprendizagem coletiva, no qual se constroem reflexões partilhadas e algumas estratégias de resolução de situações-problema. Desse modo, as famílias foram convocadas a produzir um saber sobre as afetações mútuas entre trabalho e família. Como afirmam Afonso \& Fadul (2015, p. 145), na Oficina Psicossocial, "se um campo de conhecimento, no caso a intervenção psicossocial, quer constituir um saber e uma práxis, não pode ... excluir os sujeitos e precisa incorporar a participação como motor de produção de conhecimento e de mudança".

No trabalho grupal, utilizou-se inicialmente a técnica conhecida como "tempestade de ideias" ou brainstorming. Solicitamos às participantes que verbalizassem a primeira palavra ou expressão que lhes viesse à mente quando pensavam no trabalho dos Operadores. Essa técnica propicia a emergência do maior número de ideias possível, em determinado tempo e sobre determinado assunto. Quando em grupo, torna-se mais produtiva, por haver troca de experiências e estímulo a novas percepções, constituindo-se, portanto, como um processo criativo (Ciarlini, 2014). No momento seguinte, foram organizados subgrupos, para que refletissem detidamente e de forma conjunta sobre os aspectos do trabalho dos Operadores que afetavam as famílias, e vice-versa. No terceiro momento, abrimos uma grande roda com todas as participantes para discutirmos sobre o que pensaram. E, por fim, fizemos uma avaliação do encontro.

Já a segunda ação (as visitas domiciliares) ampliou o conhecimento do cotidiano familiar, de suas moradias, das relações interpessoais e com o território. Cumpre ressalvar que esse trabalho se caracteriza pela função de sensibilização da própria equipe de pesquisa, uma vez que consistiu numa primeira aproximação com os grupos familiares dos Operadores, de modo a fortalecer nossos vínculos.

Todo o material produzido foi pesquisado a partir da análise de conteúdo de Bardin (1995), que associa a verificação meticulosa e a interpretação criativa, sempre em busca do que está além das aparências, do que se esconde por detrás das comunicações, articulando a objetividade e a subjetividade. Da análise de conteúdo, utilizamos mais precisamente sua proposta acerca do sistema de categorias, com o intuito de organizar e sistematizar os pontos a serem investigados. Desse modo, abordaremos, a seguir, as categorias de análise como agrupamentos temáticos que se destacaram nas verbalizações das famílias. São elas: percepções sobre o trabalho e seus impactos nas relações familiares; percepções sobre o território; o conflito em torno das "casas prometidas"; a importância da construção, manutenção e fortalecimento das redes sociais, entendidas aqui como um conjunto de relações interpessoais concretas que vinculam indivíduos a outros (Barnes, 1987).

13 A Psicossociologia é uma das abordagens clínicas do trabalho (Bendassolli \& Soboll, 2011), que tem como objeto de estudo e de intervenção o sujeito em sua vida cotidiana, em seus grupos, organizações e instituições, com reflexos nas questões relativas ao trabalho. Entendemos a Psicossociologia como uma possível ponte de articulação entre os campos da Psicologia Social do Trabalho e da Psicologia Organizacional, corroborando a fala de Barus-Michel et al. (2002, p. X): "A coerência interna da psicossociologia não exclui a diversidade das suas orientações, que diferem com efeito por vezes profundamente, tanto do ponto de vista dos temas e das preocupações teóricas como dos métodos e dos objetivos". 


\section{Resultados}

Percepções sobre o trabalho e seus impactos nas relações familiares

Na primeira parte do trabalho na Oficina Psicossocial, estavam presentes as esposas de alguns Operadores e os seus filhos, sendo que todos participaram da técnica de brainstorming. Posteriormente, as crianças foram para outra sala, preparada com filme e jogos, e apenas as esposas dos Operadores deram seguimento ao trabalho na oficina.

$\mathrm{Na}$ técnica do brainstorming, as famílias mencionaram as seguintes palavras: "cansaço", "coragem", "segurança", "determinação", "sono", "disposição", "esforço", "comprometido", "força de vontade", "gostar do que faz", "produção", "dedicação", sendo que as quatro primeiras foram as mencionadas mais frequentemente. Nota-se que, num primeiro momento, os familiares percebem o trabalho dos Operadores como algo desafiador, que exige comprometimento e esforço, o que resulta, em contrapartida, em cansaço. Alguns familiares mencionaram a expressão "segurança e produção", regra máxima da cultura organizacional, que também se constitui como um valor para o grupo familiar, quando se toma por referência o trabalho do Operador.

O trabalho em turnos também é mencionado pelas famílias de forma positiva e vantajosa em relação a outros complexos de mineração, pois agora os familiares conseguem passar mais tempo em casa. Os Operadores trabalhavam em regime assim definido: das $0 \mathrm{~h}$ às $6 \mathrm{~h}$; das $6 \mathrm{~h}$ às $15 \mathrm{~h}$; das $15 \mathrm{~h}$ às $24 \mathrm{~h}^{14}$. Há, por outro lado, o cansaço dos Operadores, sobretudo dos que trabalham à noite e precisam dormir durante o dia. Esses são afetados pela privação do sono no período da noite; pela diferença entre a sua rotina de trabalho e as rotinas de seus familiares; e pelo calor excessivo ${ }^{15}$, em razão de não terem instalado nas casas o sistema de ar-condicionado, por aguardarem a liberação das moradias alugadas pela empresa.

A gestão do cotidiano das famílias é relatada como sendo resultado de comum acordo entre os casais. Muitas esposas matriculam os filhos pequenos no turno escolar da tarde, quando se trata de esposos que trabalham à noite, para que estes possam ter qualidade no sono e no descanso. Há outros relatos, porém, de dificuldade em efetivamente descansar e, sobretudo, dormir. Fica perceptível, no relato de algumas mulheres, a diferença entre a organização cotidiana da família (fruto de negociação coletiva) e a organização pessoal e profissional do trabalhador (fruto de decisão individual).

Em determinado relato, por exemplo, nota-se que um trabalhador e sua esposa já se organizam no dia a dia para que ele tenha asseguradas as condições de um sono tranquilo. Ele vai para o quarto à tarde, após o almoço, e dorme, até chegar o horário de se preparar para o trabalho. Nas folgas, também dorme de dia. Para ele, trabalhar à noite afeta seu funcionamento corporal, o que, segundo afirma, impacta sua capacidade produtiva.

A esposa de outro trabalhador do turno noturno, embora reconheça que, para o marido e para a família, é bem menos cansativo o regime de descanso diurno, relata que ela mesma não consegue dormir quando o esposo está trabalhando. Nas suas palavras: "trabalho junto com ele". À noite, ela fica em alerta, qualquer barulho a assusta e acorda pensando que o marido está chegando. Ela tenta minimizar esse sentimento trancando a porta do quarto, mas só consegue dormir bem quando ele está em casa, pois se sente "segura".

Em relação às possibilidades de obtenção de trabalho das esposas, algumas relatam a expectativa de conseguir um emprego formal e obter os benefícios decorrentes desse tipo de vínculo. Uma delas explica que se dedica ao cuidado dos filhos e da casa, afirmando que, embora queira muito trabalhar, isso ainda não é possível, devido à idade dos filhos. Já outra participante aposta no trabalho informal, tal como a venda de cosméticos. Nesse caso, o trabalho parece

14 À época da realização desta intervenção psicossocial, o turno dos Operadores era caracterizado por uma jornada de $12 \mathrm{~h}$ de trabalho, sendo dois dias de trabalho e dois dias de descanso. Agora, trabalham três dias consecutivos e descansam igualmente por três dias.

15 O município no qual se localiza a mineradora situa-se na zona equatorial brasileira, que recobre praticamente toda a região Norte do país. Essa zona se caracteriza por um clima quente e úmido, sendo as médias anuais acima de $18^{\circ} \mathrm{C}$. Nessa região, especificamente, a temperatura anual varia entre $24^{\circ} \mathrm{C}$ e $30^{\circ} \mathrm{C}$ (Instituto Brasileiro de Geografia e Estatística [IBGE], 2016). 
constituir-se como fator protetivo, no que diz respeito à criação de vínculos interpessoais, ao desenvolvimento da autoestima, do sentimento de utilidade e valor pessoal, e também da independência financeira, conforme vimos com Barham e Vanalli (2012).

Certamente, há que se ressaltar a influência das relações de gênero, culturalmente estabelecidas, na composição da mão de obra empregada no mercado de trabalho: às mulheres são delegadas as funções domésticas, de cuidado para com os filhos, os familiares idosos e os doentes, em detrimento de sua projeção no trabalho (OIT, 2009, 2011). Escutamos de todas as esposas o desejo de retornar ao mercado de trabalho, mas relataram sua impossibilidade naquele momento, em virtude de suas tarefas domésticas.

Observa-se ainda, na percepção das mulheres, dificuldade de reinserção profissional, em razão do contexto socioeconômico, de poucas ofertas de postos de trabalho, além da ausência ou deficiência de equipamentos (públicos ou privados) para cuidarem de seus filhos, enquanto ambos os pais estão trabalhando. Tal percepção é convergente com outros estudos, como Palheta et al. (2017) e Koury (2014).

\section{Percepções sobre o território}

O início das atividades de pesquisa-intervenção com as famílias impôs para os pesquisadores a necessidade de ampliar o escopo teórico-metodológico previsto inicialmente, que priorizava os Operadores e sua atividade, dando pouca atenção às relações familiares e ao fato de que esses trabalhadores eram majoritariamente migrantes de outras regiões.

Ouvindo os relatos dos trabalhadores e seus familiares a respeito do processo de mudança, de instalação em novo espaço, das condições que a região apresentava, percebemos que o conceito de território (reconhecidamente mais amplo do que a noção espacial) poderia auxiliar na compreensão da dinâmica dos sujeitos pesquisados. Dentre vários autores e conceitos (Leão, 2013), escolhemos a noção de "território usado" cunhada por Milton Santos, para quem "[o território] só se torna um conceito utilizável para a análise social quando o consideramos a partir de seu uso, a partir do momento em que o pensamos juntamente com aqueles atores que dele se utilizam" (Santos, 2000, p. 22).

Os territórios constituem-se como espaços vivenciais complexos, posto que abrangem tanto um espaço físico e geográfico quanto as experiências e as histórias de cada indivíduo e dos coletivos a que ele pertence. O território envolve, portanto, tempo e espaço, memória, afetos e processos identitários, caracterizado por sua dinamicidade, afetada por dimensões como trabalho e tecnologia (Ferraz et al., 2017; Santos, 1992).

Nos relatos das famílias, foi possível observar que a percepção das pessoas sobre o território agencia modos de viver, ser e estar no mundo, afetando os processos de subjetivação e autorreconhecimento. Em um novo território, são constituídos novos modos de habitar, de relacionar com o outro e com seu espaço, novas experiências afetivas e subjetivas. As famílias estavam acostumadas com casas geralmente mais amplas e confortáveis do que os apartamentos de quatro cômodos disponíveis na região. As perdas relativas às condições de moradia e a insatisfação daí decorrente são majoradas, no caso das famílias que acompanhamos, pelo fato de que o município em que agora habitam possui poucas ofertas de lazer, saúde e trabalho, conforme relatado pelas participantes da roda de conversa. A precariedade dos serviços de lazer e cultura é ratificada na verificação da estrutura do governo municipal. Apesar de ter um dos maiores Índices de Desenvolvimento Humano (IDH) do estado do Pará, o município não possui uma Secretaria Municipal de Cultura.

Outro assunto abordado nos diálogos com as famílias foi a oscilação econômica da região, que experimentou grande expectativa de aumento de renda e incremento da economia local, como decorrência da implantação da referida unidade extrativa mineral. No período de construção dos projetos envolvendo a extração de minério, havia milhares de pessoas empregadas em diversas etapas, da construção das estradas à construção das instalações de trabalho. Ao final desse processo, findaram-se os contratos com as empresas prestadoras de serviços, efetuando-se os desligamentos correspondentes. Com efeito, a empresa contratante informa que 
aproximadamente 15.700 pessoas foram contratadas em regime precário ou temporário, durante a fase de instalação da unidade mineradora, mas a previsão de funcionários permanentes não deve ultrapassar 4.000 postos de trabalho.

Nas verbalizações das famílias, foi também possível perceber que a infraestrutura de lazer, saúde, educação e segurança do município ainda era deficitária, havendo cada vez menos interesse dos trabalhadores migrantes em permanecer nela, corroborando estudos anteriores (Ferraz et al.,2017; Villa Verde et al., 2014).

Por sua vez, os Operadores e os gestores não destacam essas mesmas lacunas no espaço social, evidenciando as distintas percepções acerca do desenvolvimento da região e sua relação com a instalação da empresa. Essa diversidade de percepções, provenientes da empresa, dos Operadores e das famílias, forma verdadeiros caleidoscópios, termo utilizado por Duarte (2015), os quais afetam todos os atores sociais envolvidos na investigação, inclusive os pesquisadores.

O conflito em relação às "casas prometidas"

Na roda de conversa realizada, o núcleo temático foram as casas prometidas pela empresa. As esposas disseram que esse tema era central em seu cotidiano familiar, provocando conflitos no convívio da família. Muitas disseram que a condição de "ganhar" uma casa da empresa foi crucial na decisão de mudar para o município. Relatam que a expectativa, em relação à entrega das casas, gerou uma cobrança por parte delas próprias, ocasionando situações que denominaram como "estresse" na relação conjugal. Algumas mulheres se queixavam da falha de comunicação, por parte da empresa, quanto ao cumprimento da promessa de aluguel das casas para os trabalhadores e suas famílias.

Curiosamente, até então, a organização não tinha dado a devida importância a essa queixa dos seus trabalhadores e de suas famílias. Nesse sentido, a presença dos pesquisadores ganha outro papel, de intermediação, que será abordado posteriormente neste texto. Para as mulheres que participaram da roda de conversa, estava claro que a ausência de um posicionamento institucional mais claro e direto, especialmente no que dizia respeito ao prazo de entrega das casas, era fator de risco psicossocial para a família e, consequentemente, para o trabalhador.

A reflexão sobre a fala dessas mulheres em torno das "casas oferecidas" ecoa sobre a expectativa da "terra prometida" (que converge com o nome do município) e explicita uma forma de sociabilidade fundada na lógica dos benefícios, entendidos como uma formulação moderna das relações de troca, imposta pela racionalidade empresarial. Essa mesma lógica extrapola, porém, sua perspectiva econômica e atinge um plano simbólico mais amplo, ao inserir-se no discurso cotidiano dos trabalhadores, dentro da organização, mesmo com os espaços de fala restritos e, talvez até por isso, aumentando os conflitos com a gestão. Como lembram Sato e Oliveira (2008, p. 195), "a gestão do trabalho não é feita apenas por aqueles reconhecidos como gestores", mas inclui os processos de regulação cotidiana de suas próprias vidas [dos trabalhadores].

Nesse caso, a empresa anuncia (ou promete) o benefício da casa para os Operadores, uma vez que o deslocamento geográfico deles é essencial para garantir a produção. Entretanto, ao não esclarecer os motivos do atraso no cronograma e, consequentemente, a perspectiva de definição do problema, acaba por provocar o aumento da insatisfação, destacando a dimensão paternalista da relação entre empresas e funcionários, típica da cultura brasileira ${ }^{16}$. Nessa organização, como em outras, dissemina-se o ideário do controle pela assistência ao empregado, de todos os modos possíveis, inclusive por meio de benefícios. Trata-se de um mecanismo de gestão da força de trabalho adotado por algumas organizações que subjetiva o controle sobre o trabalho, atingindo as chamadas medidas pró-familiares ou family-friendly-benefits (Allen citado por Teixeira \& Nascimento, 2011).

16 Teixeira e Nascimento (2011) apresentam evidências de que esse paternalismo se apresenta também na cultura portuguesa. Entretanto, para fins deste relato, concentramo-nos na situação brasileira. 
O deslocamento do controle dos trabalhadores por estratégias de ordem subjetiva, inclusive afetiva, vem sendo objeto de análise e reflexão. Para Horst et al. (2011), o foco atual das organizações está em controlar afetivamente seus trabalhadores, apresentando-se como seres grandiosos e aptos a satisfazer os desejos dos sujeitos, uma espécie de sequestro da subjetividade, de modo que "a repressão é substituída pela sedução, a imposição, pela adesão, a obediência pelo reconhecimento" (p. 60). Neste mesmo sentido, Barros e Ribeiro (2014) afirmam que as práticas não mudaram desde os tempos tayloristas/fordistas, sendo que as organizações atuais sustentam o discurso de "empresa-mãe", buscando o lucro por vias dos mesmos moldes de um capitalismo perverso.

A promessa de casa, como temática recorrente dos sujeitos, nos levou a problematizar a expressão "empresa não é mãe". A empresa é uma organização jurídico-legal e responde desse lugar. Se a empresa "promete" casa aos trabalhadores, bem como reajuste ou equiparação salarial, isso não é da ordem de uma benesse, maternal e afetiva, e sim de uma responsabilidade que ela assume frente aos seus funcionários. Por outro lado, a exigência dos trabalhadores pela moradia pode ser vista como resposta ao discurso institucional da empresa paternalista. Evidentemente, o princípio da qualidade de vida, na percepção dos familiares dos Operadores, está atrelado também a ter uma casa. Trata-se de uma relação dialética, mutuamente alimentada, que perpetua uma percepção de relativa dependência dos sujeitos em relação à organização e, por consequência, retarda processos de autonomia e responsabilização extremamente importantes até mesmo para a consecução das atividades profissionais.

Importância da construção, manutenção e fortalecimento das redes sociais

As redes sociais constituem-se para o sujeito tanto como uma fonte de apoio quanto como um componente de qualidade de vida, de interação e desenvolvimento humano. A diversificação e a estabilidade de tais redes sociais, portanto, surgem como fatores protetivos à saúde humana (Juliano \& Yunes, 2014; Moré \& Crepaldi, 2012).

Podem-se definir redes sociais como um conjunto de relacionamentos interpessoais significativos para um sujeito, uma família ou uma comunidade, do ponto de vista do suporte social, material e emocional, que constitui rede de apoio e compromisso mútuos, conforme as situações vivenciadas no cotidiano, fortalecendo os recursos pessoais e sociais para o enfrentamento de tais situações (Moré \& Crepaldi, 2012).

Algumas esposas relatam que não moram perto das famílias de origem, que estão em municípios próximos ou em outro estado, de modo que contam com o apoio da vizinhança, das amizades e de colegas de trabalho dos maridos, o que também gera alguns transtornos. Algumas conseguem constituir essas redes através da comunidade religiosa; outras relatam não ter "facilidade" em estabelecer vínculos interpessoais e se sentem mais solitárias. Há também aquelas que relatam "facilidade" de estabelecer relações de amizade, de modo que, além do contato permanente e presencial com os amigos e os familiares, fizeram amizades com outros trabalhadores e suas famílias. Para elas, essa constituição das redes de amizade é muito importante, é saudável e lhes traz alegria, além de suporte para os momentos difíceis.

Ficou explícita a percepção de que a formação de uma rede social ampla e diversa é entendida mais como fruto de características pessoais do que relacionada ao acesso a equipamentos sociais. Trata-se de uma configuração relativamente comum para os trabalhadores e suas famílias, quando precisam migrar para desenvolver suas atividades, reafirmando as ponderações de Duarte $(2015$, p. 317), para quem "a mobilidade permite explorar e descobrir novos modos de vida, mas traz desagregação e perdas".

Como seres sociais, as pessoas desenvolvem, ao longo de sua história, e conforme cada momento de seu ciclo vital, estratégias diversas para lidar com os recursos disponíveis em seu contexto, a partir dos vínculos que estabelecem, de modo a construir maior satisfação consigo mesmas, em termos de qualidade de vida e de saúde (autoestima, resiliência, autonomia) (Juliano \& Yunes, 2014). 
Nota-se, portanto, que cada família constitui suas estratégias de articulação com outras pessoas ou grupos (família extensa, comunidade religiosa, vizinhança), de acordo com suas condições concretas de possibilidade, influenciadas por fatores geográficos e psicossociais, tais como disponibilidade, maior ou menor, para estabelecer vínculos interpessoais, conforme as experiências de vida; a percepção de insegurança no território; a proximidade ou distanciamento da família extensa ou de origem.

\section{Considerações finais}

A intervenção realizada proporcionou à equipe de pesquisa o estreitamento das relações com os Operadores e suas famílias, constituindo-se em fonte potencial de ampliar nosso poder de agir, na medida em que auxiliamos na mediação de interesses. Um exemplo dessa mediação pode ser identificado na atenção que passou a ser dada pela empresa às queixas dos trabalhadores, os quais passaram a se sentir apoiados pelos pesquisadores, na medida em que suas demandas eram continuamente incorporadas às negociações cotidianas com os gestores. Assim, as casas foram entregues, alguns meses depois de nossa visita, com uma melhoria do fluxo de comunicação entre empresa, famílias e Operadores.

Conseguimos ampliar a voz dos trabalhadores e de suas famílias junto à organização, que passou a reconhecer que as condições de vida do trabalhador e de sua família afetam o desempenho no trabalho. Esse reconhecimento expressou-se inclusive no acatamento de outras ações, que serão relatadas em textos posteriores, como a implantação de grupos de convivência dos familiares e a publicação de livros com a história de vida dos trabalhadores e suas famílias.

Colocamos em debate também o relativo isolamento das famílias: todas elas estão distantes da família ampliada e de suas redes sociais usuais, e nem todas conseguem estabelecer novos vínculos de confiança e proximidade, inclusive entre si. Inferimos que isso seja influenciado pela insegurança no território (ocorrências de assaltos, por exemplo), mas também pelo distanciamento que a atividade de mineração exige do funcionário, pois comumente ocorre em lugares distantes de grandes centros urbanos.

A reconstituição de redes sociais e laços afetivos, no território, pode servir como fator protetivo para as famílias. Inclusive, uma das expectativas em torno de morar no bairro onde residem funcionários da empresa é a possibilidade de se sentirem seguras, com pessoas próximas e amigas, morando no mesmo condomínio, o que favorece as trocas (venda de produtos, oferta de serviços, ajuda no cuidado com os filhos). Em algumas famílias, por exemplo, os relatos são de que, se pudessem contar com alguém de confiança para olhar os filhos, as esposas poderiam estudar e trabalhar fora de casa, aumentando suas chances de obtenção de trabalho e de escolarização. Este argumento pode endossar a necessidade de um diálogo maior do município com a comunidade, o que, naquele momento, fugia ao escopo inicial das nossas ações de pesquisa, mas foi reportado à organização. Em consideração à dimensão interpessoal, inerente à constituição de redes sociais de apoio mútuo, seria de se esperar o papel da comunidade local, do Estado, via município, e da organização/empresa, como instâncias privilegiadas, no caso aqui estudado, para promover a solidariedade com as famílias dos trabalhadores. Esta possibilidade a constituição de redes sociais de apoio mútuo - aproxima-se da noção de "território usado", conforme proposto por Santos (2000).

Outro dado observado foi o interesse em uma boa formação para todos os membros da família. Todas as mulheres enfatizaram a importância de uma escola de qualidade para os filhos, além de incentivar os esposos a prosseguir nos estudos, a continuar sua própria formação e capacitação. Destaca-se, outrossim, o quanto o turno é determinante para sua qualidade de vida, para a qualidade do descanso, do sono e das relações sociais, de modo que essas singularidades precisam ser consideradas para o estabelecimento dos turnos de trabalho para cada Operador.

Em relação aos limites da intervenção, reconhecemos que não houve possibilidade, naquele primeiro momento, de aprofundar as questões levantadas pelas famílias e transformadas aqui em categorias analíticas. Com efeito, nosso trabalho tinha apenas o caráter de sensibilização, 
de aproximação inicial com o grupo, visando ao fortalecimento de vínculos com nossa equipe de pesquisa.

Este trabalho nos possibilitou, no entanto, ratificar a importância das pesquisas participativas, na conformação de espaços de intervenção, inclusive por interrogar o conhecimento preestabelecido e nos permitir avançar em sua afirmação, revisão e transformação. Nesse sentido, a associação entre pesquisa e intervenção é fundamental, como operador éticopolítico, ou seja, como motor para a produção de conhecimento que transforma os sujeitos e os contextos em que vivem e trabalham.

Por fim, este é o relato de uma investigação que fornece pistas para que a organização se aproxime mais da interface trabalho-família, apresentando elementos que apontem para uma visão mais integral do cotidiano dos trabalhadores, evidenciando a complexidade de fatores que compõem o binômio trabalho e vida.

\section{Referências}

Afonso, M. L. M. (2006). Oficinas em dinâmicas de grupo: um método de intervenção psicossocial. Casa do Psicólogo.

Afonso, M. L. M. \& Fadul, F. M. (2015). O trabalho com grupos no PAIF: um diálogo interdisciplinar com a Oficina de Intervenção Psicossocial. Pesquisas e Práticas Psicossociais, 10(1), 140-154. http://pepsic.bvsalud.org/pdf/ppp/v10n1/12.pdf

Arruda, M. C. C. (1996). Relação empresa-família: o papel da mulher. Revista de Administração de Empresas, 36(3), 06-13. http://dx.doi.org/10.1590/S0034-75901996000300002

Bardin, L. (1995). Análise de conteúdo. Edições 70.

Barham, E. J., \& Vanalli, A. C. G. (2012). Trabalho e família: perspectivas teóricas e desafios atuais. Revista Psicologia: Organizações e Trabalho, 12 (1), 47-59. http://pepsic.bvsalud.org/pdf/rpot/v12n1/v12n1a05.pdf

Barnes, J. (1987). Redes sociais e processo político. In B. Feldman-Bianco (Org.), Antropologia das sociedades contemporâneas: métodos (pp. 159-193). Global.

Barros, A. C. Jr., \& Ribeiro, M. A. (2014). A empresa-mãe protetora (re)vela uma dimensão perversa. Boletim de Psicologia, 63(139), 129-145. http://pepsic.bvsalud.org/pdf/bolpsi/v63n139/v63n139a03.pdf

Barus-Michel, J., Enriquez, E., \& Levy, A. (Orgs.). (2002). Dicionário de psicossociologia. Climespsi.

Bendassolli, P. F., \& Soboll, L. A. (2011). Clínicas do trabalho: novas perspectivas para a compreensão do trabalho na atualidade. Atlas.

Bernardo, M. H., Oliveira, F., Souza, H. A. D., \& Sousa, C. C. D. (2017). Linhas paralelas: as distintas aproximações da Psicologia em relação ao trabalho. Estudos de Psicologia Campinas, 34, 15-24. https://doi.org/10.1590/1982-02752017000100003

Biroli, F. (2014). Família: novos conceitos. Fundação Perseu Abramo.

Castel, R. (1998). As metamorfoses da questão social: uma crônica do salário. Vozes.

Ciarlini, J. R. (2014). Brainfood, dude! Manual criativo e ilustrado de brainstorming para comunicadores organizacionais [Monografia, Faculdade de Comunicação, Universidade de Brasília].

Duarte, D. A. (2015). (Des)encontros trabalho-família: narrativas de familiares de trabalhadores migrantes do setor de produção de energia hidrelétrica. Unesp. https://repositorio.unesp.br/handle/11449/138579

Faustino, C. \& Furtado, F. (2013). Mineração e violações de direitos: o projeto Ferro Carajás S11D, da Vale. Relatório plataforma DHESCA Brasil. http://www.global.org.br/wp-content/uploads/2016/03/plataformadhesca_carajas.pdf 
Ferraz, C. E. O., Malhado, S. C. B., Carvalho, P. A. L., Pereira, L. C., \& Sena, E. L. S. (2017). Partir e ficar de famílias em território marcado pela mineração de urânio: estudo merleau-pontyano. Saúde em Debate, 41 (115), 1033 1045. http://dx.doi.org/10.1590/0103-1104201711504

Fonseca, J. C. F., Reis, B. M. C., Monteiro, J. A. T., Vieira, C. E. C., \& Araújo, J. N. G. (2021). Psicologia, trabalho e processos psicossociais: pesquisas e intervenções. Editora PUC Minas.

Freitas, C. M. \& Silva, M. A. D. (2019). Acidentes de trabalho que se tornam desastres: os casos dos rompimentos em barragens de mineração no Brasil. Revista Brasileira de Medicina do Trabalho, 17(1), 21-29. http://dx.doi.org/10.5327/Z1679443520190405

Frone, M. R., Yardley, J. K., \& Markel, K. S. (1997). Developing and testing an integrative model of the work-family interface. Journal of Vocational Behavior, 50(2), 145-167. https://doi.org/10.1006/jvbe.1996.1577

Goulart, E., Feijó, M. R., Cunha, É. V., Corrêa, B. J., \& Gouveia, P. A. E. S. (2013). Exigências familiares e do trabalho: um equilíbrio necessário para a saúde de trabalhadores e organizações. Pensando Famílias, 17(1), 110-122. http://pepsic.bvsalud.org/pdf/penf/v17n1/v17n1a11.pdf

Hirata, H. (1986). Trabalho, família e relações homem/mulher. Reflexões a partir do caso japonês. Revista Brasileira de Ciências Sociais, 2(1), 5-12.

Hirata, H. (2004). O universo do trabalho e da cidadania das mulheres: um olhar do feminismo e do sindicalismo. In A. A. Costa, E. M. Oliveira, M. E. B. Lima, \& V. Soares (Orgs.), Reconfiguração das relações de gênero no trabalho (pp. 13-20). CUT. https://library.fes.de/pdf-files/bueros/brasilien/05632.pdf\# page=13

Horst, A. C., Cavallet, L. H., Pimenta, S. O., \& Soboll, L. A. (2011). Os vínculos frágeis no capitalismo flexível e o sequestro da subjetividade. In D. L. S. Ferraz, A. P. Oltramari, \& O. Panchirolli (Orgs.), Gestão de Pessoas e Relações de Trabalho (pp. 52-65). Atlas.

Instituto Brasileiro de Geografia e Estatística (2016). Clima. Mapa de clima do Brasil. In Atlas Escolar. https://atlasescolar.ibge.gov.br/images/atlas/mapas_brasil/brasil_clima.pdf

Juliano, M. C. C. \& Yunes, M. A. M. (2014). Reflexões sobre rede de apoio social como mecanismo de proteção e promoção de resiliência. Ambiente $\mathcal{E}$ Sociedade, 17(3), 135-154. https://doi.org/10.1590/S1414$753 \times 2014000300009$

Koury, S. C. (2014). Meio ambiente e condições de trabalho na Amazônia oriental: uma análise sobre as relações de trabalho na mineração. Revista do Tribunal Superior do Trabalho, 80 (2), 208-225.

Leão, L. H. C. (2013). Território e (in)justiça ambiental: uma agenda científica para a psicologia organizacional e do trabalho. Cadernos de Psicologia Social do Trabalho, 16(2), 183-198. https://www.revistas.usp.br/cpst/article/view/77829

Lemos, F. C. S., Santos, I. C., Ferreira, E. T. A., Sousa, L. P., \& Arruda, A. B. (2016). Paradoxos do exercício de práticas de biopoder na Amazônia paraense. Fractal: Revista de Psicologia, 28(3), 316-323. https://doi.org/10.1590/1984-0292/995

Lima, F. P. A., Rabelo, L. B. C., \& Castro, M. G. L. (2015). Conectando saberes: dispositivos sociais de prevenção de acidentes e doenças no trabalho. Fabrefactum.

Medeiros, T. J., Aguiar, J., \& Barham, E. J. (2017). Entre o conflito e o equilíbrio: ferramentas para examinar a relação trabalho-família. Revista Psicologia Argumento, $\quad$ 35-62. http://dx.doi.org/10.7213/psicolargum.35.88.AO04

Mioto, R. C. T. (2015). Política social e trabalho familiar: questões emergentes no debate contemporâneo. Serviço Social Eु Sociedade, 124, 699-720. http://dx.doi.org/10.1590/0101-6628.047 
Moré, C. L. O. \& Crepaldi, M. A. (2012). O mapa de rede social significativa como instrumento de investigação no contexto da pesquisa qualitativa. Nova Perspectiva Sistêmica, 43, 84-98. http://www.revistanps.com.br/index.php/nps/article/viewFile/265/257

Oliveira, F. (2007). A persistência da noção de ato inseguro e a construção da culpa: os discursos sobre os acidentes de trabalho em uma indústria metalúrgica. Revista Brasileira de Saúde Ocupacional, 32(115), 19-27. https://doi.org/10.1590/S0303-76572007000100003

Oliveira, L. B., Cavazotte, F. S. C. N., \& Paciello, R. R. (2013). Antecedentes e consequências dos conflitos entre trabalho e família. Revista de Administração Contemporânea, 17(4), 418-437. http://dx.doi.org/10.1590/S1415-65552013000400003

Organização Internacional do Trabalho (2009). Trabalho e família: rumo a novas formas de conciliação com responsabilidade social.

Organização Internacional do Trabalho (2011). Notas da OIT sobre trabalho e família em língua portuguesa. OIT Lisboa. https://www.ilo.org/wcmsp5/groups/public/---americas/---ro-lima/---ilobrasilia/documents/publication/wcms_229647.pdf

Palheta, J. M., Silva, C. N., Oliveira, A., \& Nascimento, F. R. (2017). Conflitos pelo uso do território na Amazônia mineral. Mercator, 16, 1-18. https://doi.org/10.4215/rm2017.e16023

Paschoal, T. \& Tamayo, A. (2005). Impacto dos valores laborais e da interferência família: trabalho no estresse ocupacional. Psicologia: Teoria e Pesquisa, 21(2), 173-180. https://dx.doi.org/10.1590/S010237722005000200007

Rey, F. L. G. (2002). Pesquisa qualitativa em Psicologia. Pioneira Thomson Learning.

Ribeiro, M., Oliveira, F., Bernardo, M. H., \& Navarro, V. (2017). Práticas em psicologia social do trabalho: pesquisa e intervenção. In M. C. Coutinho, M. H. Bernardo, \& L. Sato (Orgs.), Psicologia Social do Trabalho (pp. 103. 126). Vozes.

Rocha, L. P., Almeida, M. C. V., Silva, M. R. S., \& Cezar-Vaz, M. R. (2011). Influência recíproca entre atividade profissional e vida familiar: percepção de pais/mães. Acta Paulista de Enfermagem, 24(3), 373-380. https://doi.org/10.1590/S0103-21002011000300011

Salles, J. M. (2020, novembro). Arrabalde: a floresta difícil. Revista Piauí, 170. https://piaui.folha.uol.com.br/a-florestadificil/

Santos, M. M., Lopes, R. R., \& Cruz, T. M. (2019). Mineração e conflitos pela posse da terra em Canaã dos Carajás: o caso do acampamento Planalto Serra Dourada. In Anais da IX Jornada Internacional de Políticas Públicas. https://periodicos.ufv.br/rever/article/view/3405/1681

Santos, M. (1992). A revolução tecnológica e o território: realidades e perspectivas. In M. Santos (Org.), Geografia, tecnologia e território (pp. 7-18). Marco Zero.

Santos, M. (2000). Território e sociedade: entrevista com Milton Santos. Perseu Abramo.

Sato, L., Coutinho, M. C., \& Bernardo, M. H. (2017). A perspectiva da Psicologia Social do Trabalho. In M. C. Coutinho, M. H. Bernardo, \& L. Sato (Orgs.), Psicologia social do trabalho (pp. 11-24). Vozes.

Sato, L., Bernardo, M. H., \& Oliveira, F. (2008). Psicologia social do trabalho e cotidiano: a vivência de trabalhadores em diferentes contextos micropolíticos. Psicologia para América Latina, 15. http://pepsic.bvsalud.org/scielo.php?script=sci_arttext\&pid $=$ S1870. $350 \times 2008000400010 \& \operatorname{lng}=\mathrm{pt} \& \operatorname{lng}=\mathrm{pt}$.

Sato, L. \& Oliveira, F. (2008). Compreender a gestão a partir do cotidiano de trabalho. Aletheia, 27, 188-197. http://pepsic.bvsalud.org/pdf/aletheia/n27/n27a14.pdf 
Teixeira, R. \& Nascimento, I. (2011). Conciliação trabalho-família: contribuições de medidas adotadas por organizações portuguesas. Revista Brasileira de Orientação Profissional, 12(2), 215-225. http://pepsic.bvsalud.org/pdf/rbop/v12n2/09.pdf

Veronese, M. V. (2003). Na direção de uma psicologia social crítica do trabalho. Oficina do Ces, Portugal, 191, 1-32. https://www.ces.uc.pt/publicacoes/oficina/191/191.pdf

Villa Verde, R. B. R., Alamino, R. C. J, \& Fernandes, F. R. C. (2014). Os desafios da extração mineral na Região Norte em prol do desenvolvimento socioeconômico. In F. R. C. Fernandes, R. C. J. Alamino, \& E. R. Araujo (Orgs.), Recursos minerais e comunidade: impactos humanos, socioambientais e econômicos (pp. 13-21). CETEM/MCTI.

Endereço para correspondência

Recebido em: 20/07/2020

bcoutinho.psi@gmail.com

Revisado em: 16/08/2021

Aprovado em: 08/10/2021 